・论坛・

\title{
极小种群植物广东含笑应当被评估为极危等级
}

\author{
李西贝阳 1,2 付 琳 $^{1}$ 王发国 $1^{*}$ 邢福武 1 \\ 1 (中国科学院华南植物园植物资源保护与可持续利用重点实验室, 广州 510650) \\ 2 (中国科学院大学, 北京 100049)
}

\section{Michelia guangdongensis (Magnoliaceae), an endangered plant species with extremely small populations, should be evaluated as CR C2a(i); D}

\author{
Xibeiyang $\mathrm{Li}^{1,2}$, Lin $\mathrm{Fu}^{1}$, Faguo Wang ${ }^{1 *}$, Fuwu Xing ${ }^{1}$ \\ 1 Key Laboratory of Plant Resources Conservation and Sustainable Utilization, South China Botanical Garden, Chinese \\ Academy of Sciences, Guangzhou 510650 \\ 2 University of Chinese Academy of Sciences, Beijing 100049
}

广东含笑(Michelia guangdongensis) 是金叶含 笑(M. foveolata) 和雅致含笑(M. elegans) 的近缘种, 但三者形态特征区别明显。本种此前已知仅分布于 广东清远的英德市, 模式标本于2003年5月23日采 自木龙顶山顶处, 海拔约1,250-1,400 m (Yan et al, 2005), 尚未有过其他分布地点的报道。

我们于 2015年1月25-26日及2016年8月31日, 在广东韶关乳源瑶族自治县大布镇的广东大峡谷 省级自然保护区核心区与曲江区罗坑省级自然保 护区山体上部海拔约1,100-1,300 m的山顶矮林与 灌草从交界处调查到广东含笑的3处野外分布, 这3 处分布点两两相距 $3.76,4.02$ 和 $7.45 \mathrm{~km}$, 且分属不 同山体, 中间有多道深谷相隔。山顶矮林中的乔木 以乌冈栋(Quercus phillyraeoides)、疏齿木荷(Schima remotiserrata)、网脉山龙眼(Helicia reticulata)等常 绿树种为主(表1), 高度一般仅4-6 m。灌草丛以芒 (Miscanthus sinensis)、野古草(Arundinella anomala) 等禾草为主(表1)。广东含笑在群落中属伴生种, 采 用样线法共调查到 5 株个体, 3 处分布点分别为 3 株、 1 株和 1 株, 均为成年植株(小乔木)。所有植株均生长 良好, 但未见果实(该种春季花期 3 月, 秋季花期 10-11月), 且林下未见幼苗, 自然更新不良, 种群 结构较不健康。

该种分布点所在的山顶矮林在保护区内面积

收稿日期: 2016-10-21; 接受日期: 2016-11-25

基金项目: 韶关市第二次全国重点保护野生植物资源调查

* 通讯作者 Author for correspondence. E-mail: wangfg@scib.ac.cn
较小。原因是保护区内的地形较为特殊, 多深谷与 台地, 二者之间多以悬崖或陡坡为过渡。1998年广 东大峡谷省级自然保护区建立之前及建立初期曾 有频繁烧荒、樵采、放牧等人为干扰，导致了植被 的退化。台地顶部为受干扰的主要区域, 植被严重 退化为灌草从, 原有植被一一山顶矮林仅残存于台 地边缘至陡坡上部的狭窄地带。而山顶以下植被受 破坏程度不大。2005年, 保护区加强管理, 人为干 扰减少, 但山顶矮林至今并未明显恢复。据以往文 献报道, 我国亚热带地区的山顶矮林与邻近地区分 布的灌草丛在土壤性质上显著不同, 山顶矮林的土 壤含水量低于灌草从, 而持水能力、土壤渗透率均 高于灌草从(叶居新, 1989)。灌草从土壤氮、磷、钾 含量在当地所有植被类型中均为最低, 且土壤各层 次间营养元素含量的差异也较大( ${ }^{(1)}$, 有机碳含量亦 为当地主要植被类型中最低 ${ }^{2}$ 。山顶矮林一旦遭受 严重破坏, 则会因土壤性质改变等原因再也难以恢 复成林，而演变为长期稳定的灌从草坡，形成“假 林线”及“假林线”之上的无林景观(叶居新, 1989)。 广东含笑的生境现状即属于此类恢复困难的情况, 因此该物种生境仍处于狭窄脆弱状态。另外, 保护

(1) 林巧香 (2011) 天宝岩国家级自然保护区森林景观格局动态及其环 境效应研究. 硕士学位论文, 福建农林大学, 福州.

(2) 肖毅峰 (2013) 莽山土壤有机碳空间分布及其影响因子分析, 硕士 学位论文. 中南林业科技大学, 长沙. 
表1 在广东含笑分布区域基于样线法调查到的植物种类

Table 1 Plant species recorded with the line transect method in the distributional site of Michelia guangdongensis

\begin{tabular}{|c|c|}
\hline 物种 Species & $\begin{array}{l}\text { Drude多度 } \\
\text { Drude abundance }\end{array}$ \\
\hline \multicolumn{2}{|l|}{ 乔木 Arbor } \\
\hline 乌冈栋 Quercus phillyraeoides & 尚多 Copiosae 1 (cop1) \\
\hline 疏齿木荷 Schima remotiserrata & 尚多 cop1 \\
\hline 少叶黄杞 Engelhardtia fenzlii & 不多 Sparsal (sp) \\
\hline 杨梅 Myrica rubra & 不多 sp \\
\hline 网脉山龙眼 Helicia reticulata & 尚多 cop1 \\
\hline 硬壳柯 Lithocarpus hancei & 稀少 Solitariae (sol) \\
\hline 米槠 Castanopsis carlesii & 单株 Unicurn \\
\hline 甜槠 Castanopsis eyrei & 不多 sp \\
\hline 日本杜英 Elaeocarpus japonicus & 稀少 sol \\
\hline 密花树 Myrsine seguinii & 不多 sp \\
\hline 木荷 Schima superba & 稀少 sol \\
\hline 红雉 Castanopsis hystrix & 不多 sp \\
\hline 马尾松 Pinus massoniana & 稀少 sol \\
\hline 罗浮柿 Diospyros morrisiana & 稀少 sol \\
\hline 鼠刺 Itea chinensis & 稀少 sol \\
\hline 山苍子 Litsea cubeba & 不多 sp \\
\hline 赤杨叶 Alniphyllum fortunei & 稀少 sol \\
\hline \multicolumn{2}{|l|}{ 灌木 Shrub } \\
\hline 朱砂根 Ardisia crenata & 不多 sp \\
\hline 岗松 Baeckea frutescens & 多 Copiosae 2 (сор2) \\
\hline 刺毛杜鹃 Rhododendron championae & 稀少 sol \\
\hline 杜鹃 Rhododendron simsii & 不多 sp \\
\hline 华南桤叶树 Clethra faberi & 尚多 cop1 \\
\hline $\begin{array}{l}\text { 阔瓣含笑 Michelia cavaleriei var. } \\
\text { platypetala }\end{array}$ & 单株 Unicurn \\
\hline 金叶含笑 Michelia foveolata & 稀少 sol \\
\hline 滇白珠 Gaultheria leucocarpa var. crenulata & 不多 sp \\
\hline 南烛 Vaccinium bracteatum & 不多 sp \\
\hline 毛桃木莲 Manglietia kwangtungensis & 稀少 sol \\
\hline 华润楠 Machilus chinensis & 单株 Unicurn \\
\hline 五列木 Pentaphylax euryoides & 不多 sp \\
\hline 车轮梅 Rhaphiolepis indica & 不多 sp \\
\hline \multicolumn{2}{|l|}{ 草本 Herb } \\
\hline 芒 Miscanthus sinensis & 尚多 cop1 \\
\hline 野古草 Arundinella anomala & 多 cop2 \\
\hline 䒴 Pteridium aquilinum & 不多 sp \\
\hline 匙叶茅膏菜 Drosera spathulata & 不多 sp \\
\hline 华南龙胆 Gentiana loureirii & 不多 sp \\
\hline 地耳草 Hypericum japonicum & 不多 sp \\
\hline 里白 Diplopterygium glaucum & 稀少 sol \\
\hline 芒萁 Dicranopteris pedata & 尚多 cop1 \\
\hline 鳞籽莎 Lepidosperma chinense & 尚多 cop1 \\
\hline
\end{tabular}

区内仍有零星放养家牛四处游荡采食植被, 对该种 的生长特别是幼苗更新仍然构成威胁。

目前, 《中国生物多样性红色名录一一高等植
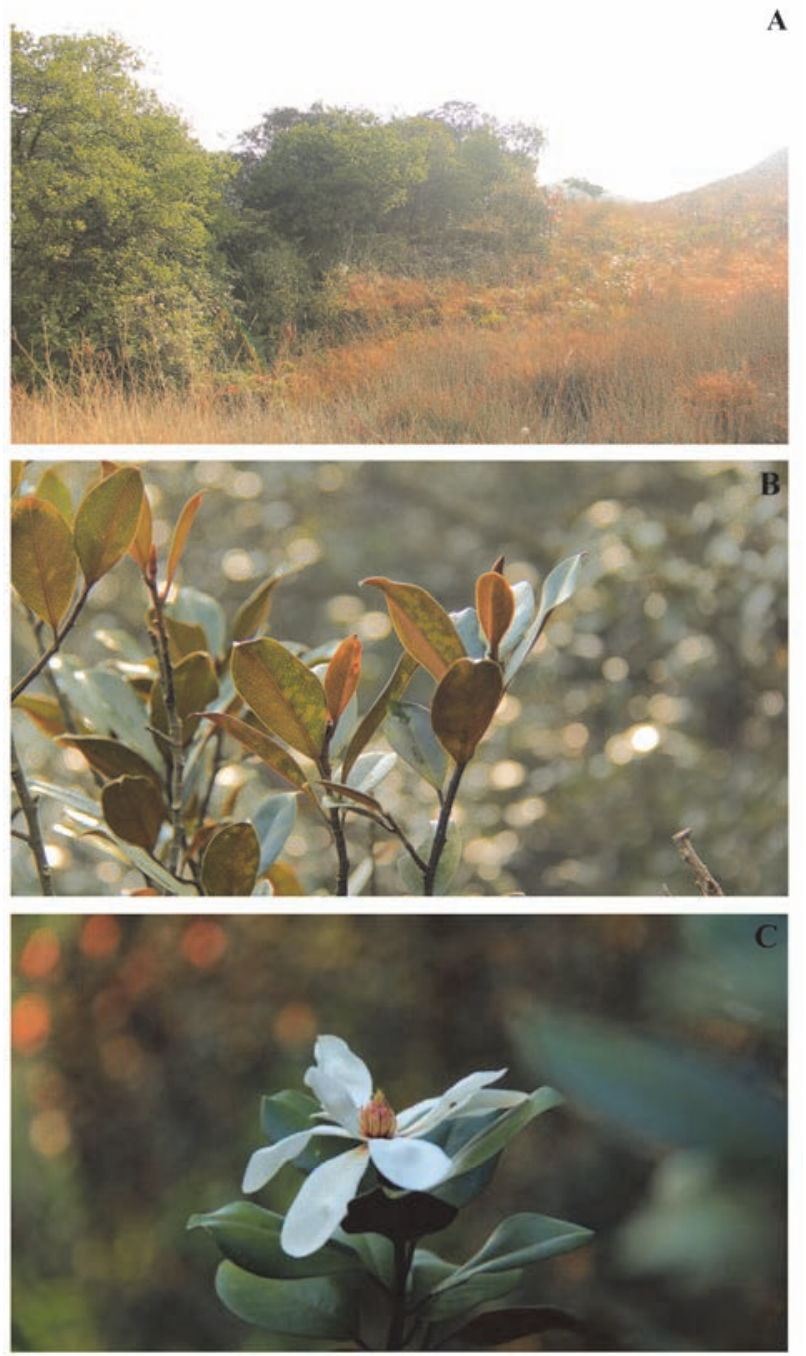

图1 广东含笑的生境和植株照片。(A) 生境; (B) 枝叶; (C) 花期。

Fig. 1 Photos showing the habitat and plant of Michelia guangdongensis. (A), Habitats; (B), Twigs; (C), Flowering phase.

物卷》将广东含笑列为濒危 $(\mathrm{EN})$ 物种(环境保护部和 中国科学院, 2013), 世界自然保护联盟(IUCN)在其 红色名录中将该种列为数据缺乏(DD)物种(IUCN, 2014)。结合本次新分布地的发现，我们认为其应当 被评估为极危(CR C2a(i); D) 等级, 因为它仅有 4 个 分布点, 成熟个体数少于 50 , 且每个亚种群成熟个 体数不超过 50 , 另外根据本次发现的分布点计算的 分布区(area of occupancy, AOO)仅有16.65 $\mathrm{km}^{2}$ 。目 前该种的迁地保护状况尚不理想, 中国科学院华南 植物园迁地栽培的植株, 实生苗常于炎热的夏季死 亡，只有嫁接苗可以存活(杨科明和陈新兰，2011); 
虽多年可见开花, 但至今未见结实。有鉴于此, 对 于该种而言, 就地保护仍然具有不可替代的重要 意义。

\section{参考文献}

International Union for Conservation of Nature (IUCN) (2014) Michelia guangdongensis is listed as Data Deficient (DD) by the IUCN Red List of Threatened Species. http://www. iucnredlist.org/. (accessed on 2016-08-12)

Ministry of Environmental Protection of the People's Republic of China, Chinese Academy of Sciences (2013) China Biodiversity Red List: Higher Plant. (in Chinese) [环境保护部 和中国科学院 (2013) 中国生物多样性红色名录一一高 等植物卷.] http://www.zhb.gov.cn/gkml/hbb/bgg/201309/ t20130912_260061.htm/. (accessed on 2016-10-02)

Yan YH, Zeng QW, Xing FW (2005) Michelia guangdongensis (Magnoliaceae), a new species from China. Annales Botanici Fennici, 41, 491-493.

Yang KM, Chen XL (2011) Introduction, breeding and landscape application of Michelia guangdongensis. Guangdong Landscape Architecture, 33(1), 44-46. (in Chinese with English abstract) [杨科明, 陈新兰 (2015) 广东含笑的引 种繁育与园林应用研究. 广东园林, 33(1), 44-46.]

Ye JX (1989) The character, ecological and economic efficiency of the subtropical hilltop fruticeta-herbosa coenosia. Jiangxi Science, 7(4), 41-48. (in Chinese with English abstract) [叶居新 (1989) 亚热带山顶灌草从的性质及其生 态、经济效益. 江西科学, 7(4), 41-48.]

(责任编辑：黄祥忠) 